\title{
Immunologic biomarkers, morbidity and mortality among HIV patients hospitalised in a Tertiary Care Hospital in the Brazilian Amazon
}

Wellington Mota Gama' ${ }^{1}$ Carlos Henrique Michiles Frank², Taynná Vernalha Rocha Almeida ${ }^{2 *}$ (D), Daniel Silva dos Santos ${ }^{3}$, Yury Oliveira Chaves ${ }^{3,4}$, Danielle Furtado da Silva ${ }^{1}$, Patrícia Puccinelli Orlandi,6, Flávio Ribeiro Pereira ${ }^{2}$, Gleicienne Feliz Magalhães ${ }^{1}$, Bárbara Jóse Baptista ${ }^{2}$, Viviane Lago de Oliveira Silva ${ }^{5}$, Antônio Alcirley da Silva Balieiro,4, Monique Freire Santana ${ }^{7}$, Roberta Lins Gonçalves ${ }^{5}$, Allyson Guimarães da Costa 1,7,8,9, Marcelo Cordeiro dos Santos ${ }^{6,7}$, Luís Carlos de Lima Ferreira ${ }^{2,5,7}$, Marcus Vinicius Guimaraes Lacerda ${ }^{2,3,7}$ and Paulo Afonso Nogueira ${ }^{1,2,3^{*}}$

\begin{abstract}
Background: The irregular use of antiretroviral therapy (ART) and late diagnosis still account for a large part of HIVassociated mortality in people living with HIV (PLHIV). Herein, we describe HIV-associated morbidity among hospitalised HIV/AIDS patients with advanced immunosuppression and assess the comorbidities, laboratory parameters, and immunological markers associated with mortality.
\end{abstract}

Methods: The cross-sectional study was conducted at the Fundação de Medicina Tropical Doutor Heitor Vieira Dourado (FMT-HVD) in Manaus, Brazil. In all, 83 participants aged between 12 and 70 years were enrolled by convenience within $72 \mathrm{~h}$ of their hospitalisation. Clinical and laboratory data were obtained from electronic medical records. We prospectively measured the cytokines Th1/Th2/Th17 and inflammatory cytokines IL-8, IL-1 3 , and IL-12 using cytometric bead array, and the soluble CD14 using in-house enzyme-linked immunosorbent assay.

Results: The HIV/AIDS inpatients presented a scenario of respiratory syndromes as the most prevalent comorbidity. Almost all patients had CD4T counts below 350 cells $/ \mathrm{mL}$ and the mortality rate was $20.5 \%$. Pulmonary tuberculosis, neurotoxoplasmosis and oropharyngeal-esophageal candidiasis were the most prevalent opportunistic infections. TB and weight loss were more prevalent in HIV/AIDS inpatients who died. The Mann Whitney analysis showed that those who died had higher platelet distribution width (PDW) on admission, which is suggestive for platelet activation. The Poisson multivariate analysis showed the prevalence of TB, digestive syndrome and increases in IL-8 and lactate dehydrogenase $(\mathrm{LDH})$ associated to death.

\footnotetext{
*Correspondence: taynnavra@gmail.com; paulo.nogueira@fiocruz.br

${ }^{1}$ Programa de Pós-Graduação em Imunologia Básica e Aplicada,

Universidade Federal do Amazonas, Manaus, Brazil

2 Fundação de Medicina Tropical Dr. Heitor Vieira Dourado, Manaus, Brazil

Full list of author information is available at the end of the article
}

(C) The Author(s) 2021. Open Access This article is licensed under a Creative Commons Attribution 4.0 International License, which permits use, sharing, adaptation, distribution and reproduction in any medium or format, as long as you give appropriate credit to the original author(s) and the source, provide a link to the Creative Commons licence, and indicate if changes were made. The images or other third party material in this article are included in the article's Creative Commons licence, unless indicated otherwise in a credit line to the material. If material is not included in the article's Creative Commons licence and your intended use is not permitted by statutory regulation or exceeds the permitted use, you will need to obtain permission directly from the copyright holder. To view a copy of this licence, visit http://creativecommons.org/licenses/by/4.0/. The Creative Commons Public Domain Dedication waiver (http://creativeco mmons.org/publicdomain/zero/1.0/) applies to the data made available in this article, unless otherwise stated in a credit line to the data. 
Conclusions: The advanced immunosuppression characterized by the opportunistic infections presented in these HIV/AIDS inpatients was the major factor of mortality. The role of platelet activation in worse outcomes of hospitalisation and the IL-8 associated with the context of advanced immunosuppression may be promising markers in the prediction of mortality in HIV/AIDS patients.

Keywords: (MeSH):HIV, Acquired immunodeficiency syndrome, AIDS-related opportunistic infections, Biomarkers, Morbidity, Mortality

\section{Background}

Brazil has been successfully combating the HIV/AIDS epidemic by providing antiretroviral therapy (ART) in a unified, universal and free public health system that is widely available to the population [1,2]. The mortality rate due to HIV/AIDS in Brazil has fallen significantly during the last 20 years, especially in the southeastern, southern and mid-western regions. This has been principally influenced by a government policy of linking HIV/ AIDS treatment and medication dispensing to compulsory notification within the public health system (Sistema Único de Saúde/SUS) $[1,3,4]$. This system has been fundamental for the decision-making process at the government level in regard to providing access to ART for all PLHIV.

Since the beginning of the epidemic in 1982, more than 300,000 deaths caused by HIV/AIDS have been reported in Brazil. After the adoption of ART in 1996, there was a significant reversal in mortality. The deaths related to the HIV/AIDS epidemic have shown a downward trend in Brazil as a whole, however this trend is still subtle in the northern and northeastern regions $[1,3,5]$. Similarly, the number of new cases of HIV/AIDS has been gradually decreasing in recent years, influenced by the southeast, southern and central-western regions, while the northern and northeastern regions still show a growth in new cases $[3,4]$.

Located in northern Brazil, the State of Amazonas has peculiar characteristics, such as geographic isolation and, in the interior of the state, a lack of access to full health services. The capital, Manaus, is the largest city in the state and its health units are decentralized, located in the neighborhoods and semi-urban areas. These health units are essential for promoting the early diagnosis and the introduction of ART, and contribute to the decrease in morbidity and mortality caused by opportunistic diseases [2]. The Fundação de Medicina Tropical Doutor Heitor Vieira Dourado (FMT-HVD) is a tertiary care hospital, which provides inpatient and outpatient care for PLHIV. The FMT-HVD is responsible for more than $85 \%$ of all patients receiving ART, and also concentrates vital data on incidence levels of AIDS, mortality rates and late diagnosis $[2,3,5-8]$. We still see many cases of virological failure and late presentation (e.g., patients presenting a late diagnosis or patients that have been infected for longer periods before being diagnosed) [2, 5, 8]. Recently, we observed in a cross-sectional study with older than 18 years of age underwent antiretroviral therapy at least 6 months [8]. This reflects in deaths related to the HIV/ AIDS, especially among PLHIV from black/brown/indigenous race/color or those having lower levels of education. As they have less access to ART or have been in discontinuous ART, the consequence is no virological suppression [6,9]. Studies on the HIV/AIDS epidemic in the Amazon region have indicated that over time the trend in the number of cases has continued to increase, principally in men. Concerning PLHIV, TB stands out as the main cause of death and respiratory failure as the main cause of hospital admission [5, 10-12].

Immune activation in HIV infection is a strong predictor of disease progression and is a result of dysregulated innate and adaptive immune responses to HIV with active participation of co-infections and microbial products [13, 14]. In PLHIV who are ART naïve or among those who have interrupted their ART, the risk of dying is higher than those who were treated continuously [15, 16]. Thus, the need to evaluate factors associated with the risk of death is increased in order to ensure an appropriate investigation and treatment during the hospitalisation of these vulnerable people. In this study, we report the prevalence of coinfections and comorbidities and assess laboratory and immunological markers within $72 \mathrm{~h}$ of hospital admission associated with the risk of death in HIV/AIDS inpatients.

\section{Methods}

\section{Study population and study design}

This cross-sectional study assessed the prevalence of comorbidities, laboratory parameters, and the immunological markers associated with the death in HIV/AIDS patients of either sex, who were admitted to the FMTHVD between 2017 and 2018. Eighty-three participants aged between 12 and 70 were enrolled in this study by convenience within $72 \mathrm{~h}$ of admission. After signature of the informed consent form, the patient's blood was collected and the serum cytokines, chemokines, and soluble CD14 were measured. 


\section{Clinical data}

During the first contact with the patients, socio-demographic data, such as name, age, gender, and use of ART, were collected. The following data were collected through the patient's electronic medical records:

- Clinic data: general health status, comorbidities, co-infections, treatment, clinical manifestations (weight loss, diarrhea, vomiting) and death.

- Laboratory data: blood count, the IgG serology test (cytomegalovirus-CMV, toxoplasmosis, Epstein Barr-EBV, herpes virus, hepatitis B virus-HBV, hepatitis $\mathrm{C}$ virus-HCV), immunological markers (viral load and T cell count CD4+ T and CD8+ $\mathrm{T})$ and biochemical markers (bilirubin, creatinine, lactic dehydrogenase, GT range, albumin, alkaline phosphatase, GPT and OGT).

\section{General characteristics of patient comorbidities}

Information regarding coinfections and comorbidities were obtained from the electronic medical database at the FMT-HVD, and the outcomes of interest were survival (hospital discharge) and death. Both were verified via either a death certificate or discharge authorization registered on the electronic medical record. Comorbidities or disorders were defined as signs and/or symptoms of respiratory, neurological, cardiovascular, and digestive origin, of infectious and non-infectious cause, with or without chronicity.

Respiratory disorders encompass a variety of pathogenic conditions that affect the respiratory tract, and include infectious and non-infectious signs and symptoms such as dyspnea (shortness of breath or difficulty in breathing), abnormal lung auscultation, long-term and/or productive cough, and pleural effusion. Neurological disorders include those of infectious and non-infectious etiology, signs and symptoms such as alteration in consciousness, sensory loss and/or movement disorders (poor coordination, tremors, asthenia), paralysis, and seizure. The cardiovascular disorders included hypertension, heart failure, peripheral edema, and anasarca. Gastrointestinal disorders include those of an infectious and non-infectious cause, signs and symptoms such as include odynophagia, dysphagia, esophagitis, gastritis, vomiting, and diarrhea.

Other comorbidities, such as chronic lymphocytic leukemia, Hodgkin's disease, aplastic anemia, and neurological disorders, such as multiple sclerosis and myasthenia gravis, were monitored.

\section{Blood sample collection}

On the same day as the patient's enrollment, after the interview and signing of the consent form, $5 \mathrm{~mL}$ of blood was collected by vacuum venipuncture. The samples were collected in dry tubes and centrifuged at $3500 \mathrm{rpm}$ for $5 \mathrm{~min}$ at $25{ }^{\circ} \mathrm{C}$ to obtain the serum and aliquoted $(1 \mathrm{~mL})$ for analysis of the inflammatory markers. The whole blood that was collected in an anticoagulant tube was homogenized, aliquoted $(1 \mathrm{~mL})$, and then stored for future analysis. Samples were stored at $-80{ }^{\circ} \mathrm{C}$ until use.

\section{Immunological markers}

The measurement of serum cytokines was performed using the flow cytometry technique CBA (cytometric bead array) with the human cocktail Th1/Th2/Th17 cytokine for IL-2, IL-4, IL-6, IL-10, TNF- $\alpha$, IFN- $\gamma$ and IL17 and inflammatory cytokines IL-8, IL-1 $\beta$, and IL-12 (Biosciences, USA). Serum concentrations of soluble CD14 (sCD14) were determined by in-house enzymelinked immunosorbent assay (ELISA). Initially, the plate was sensitized with the primary antibody (anti-human CD14 Antibody; Cat. №. MAB3833; Lot. AWI091610A; R\&D Systems) diluted in carbonate-bicarbonate buffer (0.05 M; pH 9.6). After sensitization, blocking was performed with PBS/BSA blocking buffer (PBS pH 7.4; 3\% bovine albumin). Subsequently, the sera from patients and controls were diluted into PBS/BSA dilution buffer (PBS pH 7.4; 0.5\% bovine albumin) and incubated for $1 \mathrm{~h}$ at $37{ }^{\circ} \mathrm{C}$. Three concentrations of recombinant human CD14 protein (Recombinant Human CD14; Cat. No. 383-CD; Lot. BCS1716091; R\&D Systems) were added to each plate well in order to determine a standard-curve. After four lavage steps in PBS washing buffer (PBS pH 7.4; $0.05 \%$ Tween 20), the 1:1000 dilution secondary antibody (anti-human CD14 Biotinylated Antibody; Cat No BAF383; Lot. BAR0714031; R\&D Systems) was added. After the lavage steps, 1:1000 dilution, $0.5 \mathrm{mg}$, peroxidase-labeled streptavidin (KPL) was added for $1 \mathrm{~h}$ at $37^{\circ} \mathrm{C}$. The reaction was developed with developing buffer (citrate-phosphate buffer $+\mathrm{TMB}+\mathrm{H}_{2} \mathrm{O}_{2} 30 \%$ ) and stopped with $\mathrm{H}_{2} \mathrm{SO}_{4}(2.0 \mathrm{M})$. The reading was made by colorimetric means (optical density-OD), using a spectrophotometer for an ELISA plate reader (Bio-Rad $\mathrm{iMark}^{\mathrm{TM}}$ microplate reader) at an absorbance of $450 \mathrm{~nm}$.

\section{Statistical analysis}

Data were tabulated in an Excel database created by the researchers and analyzed using the GraphPad Prism program, version 7. For data analysis, patients were defined as Death (those who died during hospitalisation) 
or Discharge (those who were discharged from hospital). Descriptive analysis was performed with mean and standard deviation (SD) for numerical variables when distribution was normal, or median and interquartile range for non-normal distributions. In the univariate analysis, Fisher's exact test was used to determine relative risk among categorical variables. Laboratory parameters, soluble CD14, cytokine and chemokines concentrations, and days of hospitalisation were compared between the Death and Discharge groups using the Mann Whitney test. The Poisson regression was performed to assess factors associated with death in HIV/AIDS inpatients among the most prevalent comorbidities, laboratory parameters and immunological markers. For this model, we used data from univariate analyses where the selected variables were those presenting $\mathrm{p}<0.2$. The statistical significance was defined as $\mathrm{p}<0.05$.

\section{Results}

Overall, respiratory disorders were the most prevalent (62.1\%), followed by neurological (37.9\%), gastrointestinal (21.0\%) and cardiovascular (5.2\%) disorders. Among the respiratory disorders of infectious cause, TB was the most prevalent $(56.30 \%)$, followed by pneumocystosis $(2.4 \%)$. The most prevalent signs and symptoms were abnormal lung auscultation (22.40\%), followed by respiratory failure (5.30\%), and severe cough (5.30\%). Regarding neurological disorders, the most prevalent coinfections were neurotoxoplasmosis (44.4\%), neurocriptococcosis (8.3\%), and neurotuberculosis (2.8\%). The most prevalent signs and symptoms were confusion, paralysis, and/or poor coordination (30.6\%), tremors and asthenia (11.1\%), and seizures $(5.6 \%)$. The most prevalent gastrointestinal disorders of infectious cause were oral and esophageal candidiasis (55\%). The most prevalent signs and symptoms were vomiting (39.7\%), diarrhea (33.7\%), and odynophagia (5.0\%). A total of $25 \%$ of patients reported abdominal pain.

In all, 17 hospitalised patients died and 66 were discharged. The duration of hospitalisation did not differ between the two groups $(\mathrm{p}=0.30)$, the median and $25 \%$ and $75 \%$ interquartiles of hospitalised days of those who died were 19 (14.5-26.5), while for those who were discharged the median was 25 (11.0-38.0). All the described disorders were assessed to identify factors associated with the mortality of the patients (Table 1). Tuberculosis was more prevalent among patients who died $(p=0.001)$. The IgG serological tests used for previous infections did not differ between HIV/AIDS patients who died or were discharged from hospital. Weight loss was associated with death $(p=0.013)$. The univariate analyses of HIV-RNA $>1000$ copies and CD4 $\mathrm{T}<350$ cells $/ \mathrm{mL}$ showed no association with death. The
Table 1 Assessment of comorbidities in the outcomes of HIVAIDS inpatients

\begin{tabular}{|c|c|c|c|}
\hline Clinical data & $\begin{array}{l}\text { Death } \\
N=17\end{array}$ & $\begin{array}{l}\text { Discharge } \\
N=66\end{array}$ & $p$ \\
\hline Age (mean, std.) & $37.6(9.9)$ & $36.2(9.4)$ & 0.590 \\
\hline Gender (male) & $11(64.7)$ & $54(81.8)$ & 0.184 \\
\hline ART & $12(70.6)$ & $55(83.3)$ & 0.300 \\
\hline CD4T $<350$ cells/mL & $14(82.4)$ & $58(87.9)$ & 0.688 \\
\hline HIV-RNA > 1000 copies & $14(82.4)$ & $47(71.2)$ & 0.539 \\
\hline Weight loss & $14(82.4)$ & $30(45.5)$ & $0.007^{* *}$ \\
\hline Very good condition & $7(41.2)$ & $35(53.0)$ & 0.425 \\
\hline Lucid and space-oriented & $8(47.1)$ & $40(60.6)$ & 0.410 \\
\hline Anemia & $15(88.2)$ & $43(65.2)$ & 0.079 \\
\hline Respiratory disorder & $14(82.4)$ & $42(63.6)$ & 0.244 \\
\hline Neurological disorder & $8(47.1)$ & $29(43.9)$ & 0.999 \\
\hline Cardiovascular disorder & $2(11.8)$ & $2(3.0)$ & 0.184 \\
\hline Gastrointestinal disorder & $8(47.1)$ & $16(24.2)$ & 0.077 \\
\hline \multicolumn{4}{|l|}{ Active coinfections } \\
\hline Tuberculosis & $12(70.6)$ & $25(37.9)$ & $0.026^{*}$ \\
\hline Parasites in stools & $3(17.6)$ & $13(19.7)$ & 0.999 \\
\hline Toxoplasmosis lgM & $1(5.9)$ & 7 (10.6) & 0.999 \\
\hline Cytomegalovirus IgM & $1(5.9)$ & $2(3.0)$ & 0.502 \\
\hline Epstein Barr virus IgM & $17(100)$ & $66(100)$ & 0.999 \\
\hline Herpes virus IgM & $0(0)$ & $3(4.5)$ & 0.999 \\
\hline \multicolumn{4}{|l|}{ Previous infections } \\
\hline $\mathrm{HCV} \lg G$ & $1(5.9)$ & $2(3.0)$ & 0.502 \\
\hline Cytomegalovirus lgG & $13(76.5)$ & $53(80.3)$ & 0.741 \\
\hline Toxoplasmosis lgG & $13(76.5)$ & $52(78.8)$ & 0.999 \\
\hline Epstein Barr virus lgG & $12(70.6)$ & $49(74.2)$ & 0.764 \\
\hline Herpes virus lgG & $12(70.6)$ & $44(66.7)$ & 0.999 \\
\hline
\end{tabular}

*,**: $p$-value; statistically significant difference

CD4 $\mathrm{T}$ counts were greatly reduced in both groups, the CD8 $T$ cells presented normal values in the group of patients who died, while the Discharge group tended towards a slight increase, though this was not statistically significant. The ratio of CD4:CD8 cells below 0.20 due the reduction of CD4-T evidenced the advanced immune impairment of the patients (Table 2).

The low hemoglobin level was present in both groups; however, it was more prevalent in those who died. The total leukocytes, neutrophils, and monocytes did not differ between groups and remained in normal ranges in most patients. The percentage of lymphocytes in those who died showed a tendency to be lower. The eosinophil counts were reduced in both groups, though they were even lower $(p=0.03)$ in those who died. The platelet distribution width (PDW) was higher among those who died. 
Table 2 Univariate analyses with laboratory parameters in the outcomes in HIV/AIDS patients

\begin{tabular}{|c|c|c|c|}
\hline Laboratory tests & $\begin{array}{l}\text { Death } \\
N=17\end{array}$ & $\begin{array}{l}\text { Discharge } \\
N=66\end{array}$ & $p$ \\
\hline \multicolumn{4}{|l|}{ Hematological data (NVA) } \\
\hline HIV-RNA copies/mL ${ }^{b}$ & $126,578(3247-273,012)$ & $25,258.5(391.5-145,976.8)$ & 0.590 \\
\hline Lymphocytes (percent) $)^{\mathrm{a}}(25.0-40.0 \%)$ & $20.5(10.3)$ & $27.4(13.5)$ & 0.055 \\
\hline CD4-T cells/ $/ \mathrm{L}^{\mathrm{b}}$ (600 to $1500 / \mathrm{mm}^{3}$ ) & $44(7-232)$ & $79(30-198.2)$ & 0.140 \\
\hline CD8-T cells/ $\mu L^{b}$ (200 to 800/mm³) & $402(198-776)$ & $544.5(359.2-1143.8)$ & 0.312 \\
\hline CD4/CD8 ratio (1.0 and 4.0) & $0.1(0-0.4)$ & $0.1(0.1-0.3)$ & 0.123 \\
\hline Hemoglobin (13.0-18.0 g/dL) & $9.3(2.7)$ & $10.8(2.4)$ & 0.165 \\
\hline Leukocytes $^{\mathrm{b}}(4500-11,000 / \mathrm{mL})$ & $4740(3510-8600)$ & $4215(3275-5,757.5)$ & 0.527 \\
\hline Neutrophils ${ }^{b}(1800-7700 / m L)$ & $2660(1679-3234)$ & $3118(2109-4907.5)$ & 0.113 \\
\hline Monocytes $^{\mathrm{b}}(80-1100 / \mathrm{mL})$ & $249(161-379)$ & $329(187.2-488.2)$ & 0.370 \\
\hline Eosinophils ${ }^{b}(40-550 / m L)$ & $2(2-4)$ & $4(2.6-7)$ & $0.030^{*}$ \\
\hline Platelets $^{\mathrm{a}}\left(150,000-400,000 \times 10^{3} / \mathrm{mL}\right)$ & $299,352.9(207,630.4)$ & $273,947.0(132,454.6)$ & 0.536 \\
\hline $\mathrm{MPV}^{\mathrm{b}}$ (8.8fL to $\left.12.5 \mathrm{fL}\right)$ & $8.2(7.8-8.8)$ & $8.1(7.4-8.7)$ & 0.446 \\
\hline $\mathrm{PDW}^{\mathrm{b}}$ (9.3 fL to $\left.16.0 \mathrm{fL}\right)$ & $15.8(13-18.7)$ & $13.5(11.2-16.5)$ & $0.037^{*}$ \\
\hline \multicolumn{4}{|l|}{ Biochemistry parameters (NVA) } \\
\hline Bilirubin $^{\mathrm{b}}(<1.0 \mathrm{mg} / \mathrm{dL})$ & $0.4(0.2-0.9)$ & $0.4(0.3-0.7)$ & 0.999 \\
\hline Creatinine $^{\mathrm{b}}(0.6-1.35 \mathrm{mg} / \mathrm{dL})$ & $1(0.7-1.3)$ & $0.8(0.6-0.9)$ & 0.069 \\
\hline $\mathrm{LDH}^{\mathrm{b}}(120$ and $246 \mathrm{U} / \mathrm{uL})$ & $435(332-534)$ & $367.5(300.2-474.2)$ & 0.159 \\
\hline Gamma-glutamyltransferase $e^{b, c}$ & $88(42-203)$ & $103.5(57.8-290)$ & 0.876 \\
\hline Albumin $^{\mathrm{b}}(3.5-5.0 \mathrm{~g} / \mathrm{dL})$ & $3.4(2.8-4)$ & $3.8(3.3-4.5)$ & 0.129 \\
\hline Alkaline phosphatase ${ }^{\mathrm{b}}$ (65.0-330.0 U/uL) & $282(200-459)$ & $281(201-386)$ & 0.835 \\
\hline Aspartate aminotransferase ${ }^{\mathrm{b}}(2-38.0 \mathrm{U} / \mathrm{uL})$ & $44(26-82)$ & $34(25-58)$ & 0.280 \\
\hline Alanine aminotransferase ${ }^{\mathrm{b}}(2-44.0 \mathrm{U} / \mathrm{uL})$ & $31(22-41)$ & $43(31-77)$ & $0.038^{*}$ \\
\hline
\end{tabular}

NVA Normal values in adults, PDW Platelet distribution width, MPV Mean platelet volume, $L D H$ lactate dehydrogenase

${ }^{a}$ Mean and standard

${ }^{\mathrm{b}}$ Median (25th; 75th interquartile)

' References values of Gamma-glutamyltransferase (men: 10 to $50 \mathrm{U} / \mathrm{uL}$ and women: 7 to $32 \mathrm{U} / \mathrm{uL}$ )

${ }^{*},{ }^{* *}: p$-value; statistically significant difference

Overall, the patients preserved their liver function, with no significant alterations in the hepatic markers. The alkaline phosphatase levels and the transaminase levels were slightly elevated in both groups. The renal function was able to maintain the creatinine levels in normal ranges (Table 2).

The soluble CD14, the chemokines and Th1/Th2/Th17 cytokine levels at the time of hospitalisation revealed no difference between the two groups, while IL-8 tended to be associated with death $(\mathrm{p}=0.06)$ (Fig. 1). It is worth mentioning the stratification of immunological markers in descending order of plasma levels.

When isolated, the prevalence of $\mathrm{TB}$ showed a relative risk (RR) of 4.62, though, when associated with digestive syndrome, it presented $R R=3.07$. In relation to laboratory parameters and immunological markers, the risk of death increases along with the increment in IL-8 and LDH levels, e.g., IL-8 $(R R=1.0001)$ and LDH $(\mathrm{RR}=1.0007)$. The mean IL-8 in univariate analysis showed no differences between groups; however, most patients who died had higher levels of IL- 8 than those who were discharged (Fig. 1B). The RR of the lymphocyte percentage was 0.9503 , indicating that the risk of death was higher as the percentage decreased (Table 3).

\section{Discussion}

After the advent of ART, HIV infection has changed from an illness that causes rapid deterioration to a complex chronic disease. Brazil has responded to the HIV pandemic in innovative ways, and was the world's first developing country to offer ART free of charge to all PLHIV and the third developing country to provide ART regardless of $C D 4+T$ cell counts $[1,17]$. As a consequence, the HIV/AIDS mortality rate continues to fall [3]. However, the states of Acre, Amazonas, and Roraima in northern Brazil still show increases in mortality. PLHIV with poorer outcomes in these states have a strong association with both late diagnosis and their 


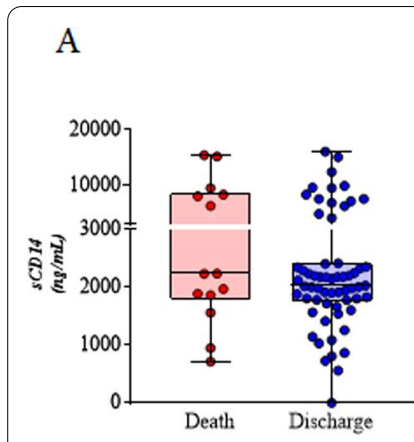

E

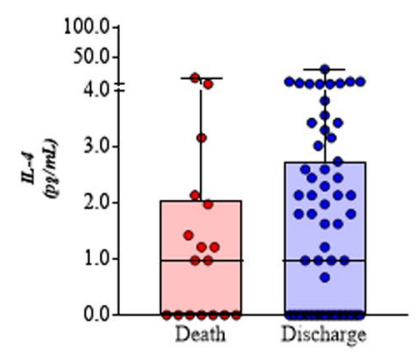

I

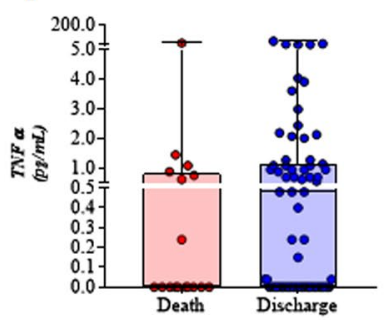

B

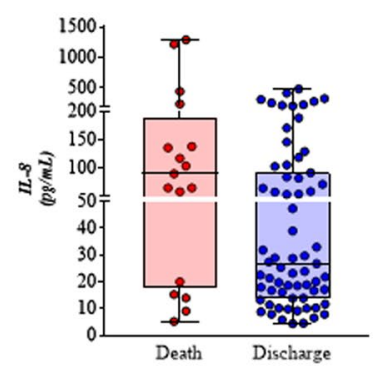

F

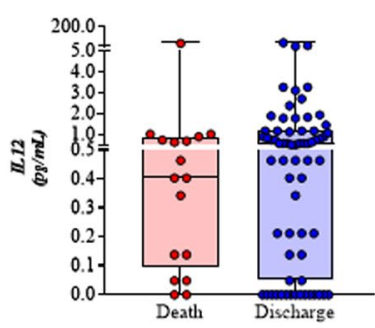

J

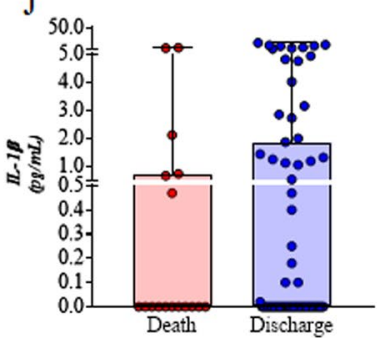

C

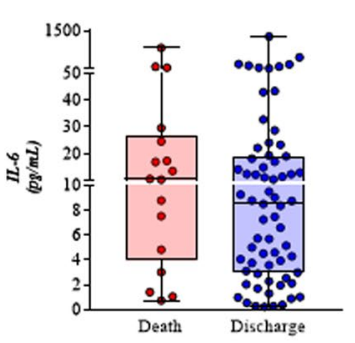

G

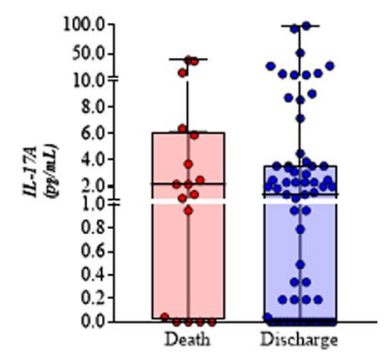

$\mathrm{H}$

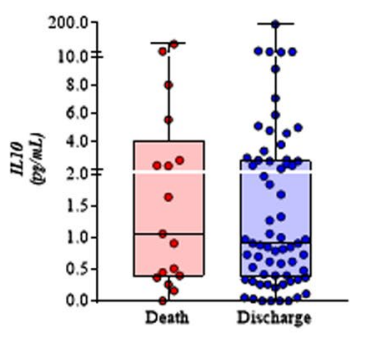

Fig. 1 Serological markers as predictors of mortality. The soluble CD14, the chemokine IL-8 and the cytokines Th1/Th2/Th17 were compared among the patients who died and those who survived. A sCD14; B IL-8; C IL-6; D IFNY; E IL-12; F IL-2; G IL-4; H IL-17A; I IL-10; JTNFa and L IL-1ß. Concentrations were compared between Death and Survival groups using the Mann Whitney test

Table 3 Relative risk of comorbidities, laboratory parameters and immunological markers in the mortality of HIV/AIDS patients

\begin{tabular}{|c|c|c|c|c|c|}
\hline \multirow[t]{3}{*}{ Characteristic } & \multicolumn{2}{|l|}{ Death } & \multirow[t]{3}{*}{$\mathbf{R R}$} & \multirow[t]{3}{*}{$95 \% \mathrm{Cl}$} & \multirow[t]{3}{*}{ p-value } \\
\hline & Yes & No & & & \\
\hline & $\mathrm{N}=17$ & $\mathrm{~N}=66$ & & & \\
\hline Digestive syndrome $e^{\mathrm{a}}$ & $8 / 17(47 \%)$ & $16 / 66(24 \%)$ & 3.05 & $(1.55-6.06)$ & 0.001 \\
\hline Tuberculosis $^{\mathrm{a}}$ & $12 / 17(71 \%)$ & $25 / 66(38 \%)$ & 4.62 & $(1.87-11.36)$ & 0.001 \\
\hline IL.8 pg/mL ${ }^{\mathrm{b}}$ & $90.4(20-189.0)$ & $26.1(14.0-90.1)$ & 1.01 & $(1.00-1.01)$ & 0.007 \\
\hline Lymphocytes $^{\mathrm{b}}$ in percentage & $20.5(10.3)$ & $27.4(13.5)$ & 0.95 & $(0.91-0.98)$ & 0.003 \\
\hline LDH U/uL** (120 and $246 \mathrm{U} / \mathrm{uL})$ & $435(332-534)$ & $367.5(300.2-474.2)$ & 1.01 & $(1.00-1.01)$ & 0.001 \\
\hline
\end{tabular}

Relative risk; $\mathrm{Cl}$ : confidence interval; and the $\mathrm{p}$-value was calculated using the Poisson regression; $\mathrm{LDH}$ : lactate dehydrogenase

${ }^{a}$ Among the categorical variables, the statistics were presented as $n / N(\%) ;$ where $n=$ number of patients for whom the variable was positive. $N$ represents total number in each group

${ }^{\mathrm{b}}$ Among the numerical variables, statistics were presented as median (Q1-Q3) or mean (SD)

**: References value of lactate dehydrogenase (120 and $246 \mathrm{U} / \mathrm{uL}$ ) 
consequent late assistance, and virologic failure (nonachievement or non-maintenance of undetectable viral load). The sociodemographic determinants, such as poverty, race/color (black/brown/indigenous), schooling, and social vulnerability index are still an obstacle for accessing timely diagnosis and proper treatment [3, 6-8].

This cross-sectional study has found that the HIV/ AIDS epidemiological scenario has not changed in the few last years; respiratory disorders are still the most prevalent complication, while $\mathrm{TB}$, neurotoxoplasmosis, and oropharyngeal-esophageal candidiasis are the most prevalent opportunistic infections. During the last decade, TB has been highly prevalent among HIV/AIDS patients who died [5, 10, 11, 18]. Additionally, we found weight loss associated to death through the univariate analysis, in agreement with early mortality in TB-HIV coinfected patients presenting malnutrition or low body mass index $[19,20]$. It is worth mentioning that weight loss and gastrointestinal disorders can be correlated variables [20]. Our multivariate analysis corroborated greater risk of death among those TB-HIV coinfected patients, similar with those coming from low-income regions, whose poverty, schooling, and social vulnerability index decrease the odds of access ART $[6,19,21-26]$. We observed an augmented risk of death among those patients presenting gastrointestinal disorders, especially oropharyngeal-esophageal candidiasis, which is recognized as an indicator of advanced immunosuppression [27]. This fungal infection is helping physicians to diagnose the clinical progression and risk of death [27, 28].

Another challenge is the patients' low adherence to ART. Despite the free access to the antiretroviral drugs, due to several reasons including social factors, side effects or skepticism, since many have experienced previous treatment failure, some patients abandon ART [29]. In the latter cases, we observed both high prevalence of individuals with virologic failure without viral drug resistance mutations (DRMs) and an increment of transmitted HIV-DRMs, which has contributed to one of the worst epidemiological scenarios in northern Brazil in the last few years [8].

As almost all HIV-infected patients from both groups showed the CD4 counts lower than 200 cells/uL. However, the risk of death associated with decreased CD4 was especially a result of TB prevalence associated with oropharyngeal-esophageal candidiasis. The univariate analysis showed higher PDW at the time of admission of the patients who died. PDW is a platelet activation marker, since, under activation, platelets increase in number and size of pseudopodia, affecting their distribution width [30]. Platelets are small, anucleate cells that have hemostatic and inflammatory proprieties, and are considered more than just innocent bystanders. Our findings point towards the platelet activation being associated with severity of the systemic inflammatory responses in TB and bacterial sepsis [31-33].

HIV/AIDS is characterized by a state of chronic immune activation and inflammation. Elevated levels of IL8 have been reported in plasma, serum and cerebrospinal fluid in HIV/AIDS patients with CD4+ T cell counts $<350$ cells $/ \mathrm{mm}^{3}$, a promising marker of the inflammatory process [34-36]. Our multivariate analysis evidenced the association of digestive disorder, TB, elevated levels of IL-8 and LDH, and low levels of CD4 with increased risk of death [37-40].

IL-8 is a prominent neutrophil chemoattractant produced by macrophages and plays a dual role in the pathogenesis of TB and HIV-1 coinfection. On the one hand, IL-8 performs a key role in killing $M$. tuberculosis by phagocytosis in in vitro studies [41, 42]. On the other hand, it enhances HIV-1 replication in monocyte derived macrophages and $\mathrm{T}$ lymphocytes $[41,43]$. An important mechanism of host defense against TB is the granuloma. IL- 8 has a significant role since it regulates the leukocyte influx in its formation. One in vivo study demonstrated that pretreatment with anti-IL-8 alone inhibits mycobacterial granuloma formation [44, 45]. Moreover, IL-8 is a major inflammation-associated cytokine in pneumonia, and is correlated with neutrophil infiltration of the lung and impairment of the gas exchange [37]. In this context, an elevated IL-8 level was considered to be a factor associated with higher mortality in HIV/AIDS patients with opportunist infections, especially those precipitating respiratory disorders such as bacterial, viral and fungal pneumonia [35-40, 46, 47]. Therefore, our findings are in agreement with studies that show that IL-8 may be used as a serological predictor for death in a scenario of advanced HIV/AIDS with TB and fungal coinfections [46, 48-52].

The sample size was one limitation of this study, and restricted the detection of other associations. Several factors contributed to the limitation of the sample, one of which is that the study was carried out in a mediumsized hospital. In addition to the structural limitations, some patients were hospitalised for up to 2 months, and others were re-hospitalised. Nevertheless, our limited sample size (by convenience) is still representative of the HIV/AIDS population in the region. Before ART, Kaposi's sarcoma and pneumocystosis were the most prevalent opportunistic diseases; after ART, TB, bacterial pneumonia and histoplasmosis became the most frequent causes of death. This study sampling was able to represent the same epidemiological scenario regarding HIV/AIDS patients that has been prevalent in northern Brazil in recent years. 
Another limitation was related to the study design, which did not include patients' follow up, only one single blood sample collection. The information regarding the deaths of patients was obtained solely via electronic medical records.

\section{Conclusions}

This cross-sectional study found that the HIV/AIDS epidemiological scenario remains unchanged in northern Brazil, e.g., greater risk of death among the TB-HIV coinfected patients and among those with advanced immunosuppression, characterized by the presence of oropharyngeal-esophageal candidiasis. The univariate analysis showed higher PDW on hospital admission, indicating platelet activation, though further studies are needed to assess their relationship with the severity of the pulmonary infection in HIV/AIDS patients. Nonetheless, the use of IL- 8 as a serological predictor of death in the HIV/AIDS patients is promising.

\begin{abstract}
Abbreviations
AIDS: Acquired immunodeficiency syndrome; ART: Antiretroviral therapy; CBA: Cytometric bead array; Cl: Confidence interval; CMV: Cytomegalovirus; EBV: Epstein Barr virus; FMT-HVD: Fundação de Medicina Tropical Dr. Heitor Vieira Dourado; HBV: Hepatitis B virus; HCV: Hepatitis C virus; HIV: Human immunodeficiency virus; IFN: Interferon; IL: Interleukin; MPV: Mean platelet volume; NVA: Normal values in adults; PDW: Platelet distribution width; RR: Relative risk; TB: Tuberculosis; TNF: Tumor necrosis factor.
\end{abstract}

\section{Acknowledgements}

We gratefully acknowledge the partnership with the INProg-HIV group.

\section{Authors' contributions}

WMG, GM, DSS, DFS, PPO, FRP, GFM, BJB, VLOS, and RLG were responsible for the data collection from medical records. WMG, YOC, and AGC performed immunoassays. TVRA, AGC, and AASB performed the statistical analyses. MCS, MVGL, TVRAA, MFS, LCLF and PAN participated in study design. TVRA, MFS, LCLF and PAN wrote the first draft of the manuscript. CHMF, TVRA, and PAN elaborated the final version of manuscript. All authors read and approved the final manuscript.

\section{Funding}

TVRA and BJB received a post-doctoral fellowship from "Programa Nacional de Cooperação Acadêmica na Amazônia" of Coordenação de Aperfeiçoamento de Pessoal de Nível Superior-Brazil (PROCAD-AM 88887.321243/2019-00). WMG and DFS each received a master's grant 119 from Programa PosGraduação em Immunologia Basica e Aplicada" at the Universidade Federal 120 do Amazonas. MVGL and PAN are CNPq fellows, levels I and II, respectively. This work was funded by a grant from Fundação Oswaldo Cruz_-Programa INOVA_Geração do Conhecimento number VPPCB-007-FIO-18, call 28/2018. The funders had no role in study design, data collection and analysis, decision to publish, or preparation of the manuscript.

\section{Availability of data and materials}

The datasets used and/or analyzed during the current study are available from the corresponding author on reasonable request.

\section{Declarations}

Ethics approval and consent to participate

All protocols and consent forms were approved by the Fundação de Medicina Tropical Dr. Heitor Vieira Dourado Ethics Review Board (CAAE:
57330116.6.0000.0005). All consent forms were signed by the research participants and filed for future verification.

\section{Consent for publication}

Not applicable.

\section{Competing interests}

The authors declare that they have no competing interests.

\section{Author details}

${ }^{1}$ Programa de Pós-Graduação em Imunologia Básica e Aplicada, Universidade Federal do Amazonas, Manaus, Brazil. ${ }^{2}$ Fundação de Medicina Tropical Dr. Heitor Vieira Dourado, Manaus, Brazil. ${ }^{3}$ Programa de Pós-Graduação em Biologia da Relação Patógeno Hospedeiro, Instituto Leônidas e Maria Deane, Manaus, Brazil. ${ }^{4}$ Programa de Pós-Graduação em Biologia Parasitária, Instituto Oswaldo Cruz, Rio de Janeiro, Brazil. ${ }^{5}$ Programa de Pós-Graduação em Ciências da Saúde, Universidade Federal do Amazonas, Manaus, Brazil. ${ }^{6}$ Instituto Aggeu Magalhaes, Fundação Oswaldo Cruz-Fiocruz, Recife, Brazil. ${ }^{7}$ Programa de Pós-Graduação em Medicina Tropical, Universidade do Estado do Amazonas, Manaus, Brazil. ${ }^{8}$ Diretoria de Ensino e Pesquisa, Fundação Hospitalar de Hematologia e Hemoterapia do Amazonas, Manaus, Brazil. ${ }^{9}$ Programa de Pós-Graduação em Ciências Aplicadas à Hematologia, Universidade do Estado do Amazonas, Manaus, Brazil.

Received: 23 August 2020 Accepted: 12 August 2021

Published online: 26 August 2021

\section{References}

1. Benzaken AS, Pereira GFM, Costa L, Tanuri A, Santos AF, Soares MA. Antiretroviral treatment, government policy and economy of HIV/AIDS in Brazil: is it time for HIV cure in the country? AIDS Res Ther. 2019;16:1-7. https://doi.org/10.1186/s12981-019-0234-2.

2. Leon C, Koosed T, Philibert B, Raposo C, Benzaken AS. HIV/AIDS health services in Manaus, Brazil: patient perception of quality and its influence on adherence to antiretroviral treatment. BMC Health Serv Res. 2019;19:1-11.

3. BRASIL M da S. Boletim Epidemiológico HIV / Aids | 2020. Secr Vigilância em Saúde. 2020;1:68.

4. Ministério da Saúde do Brasil. Boletim Epidemiologico HIV Aids 2017. HIV Aids Bol Epidemiológico. 2017:64.

5. Oliveira RDSMD, Benzaken AS, Saraceni V, Sabido M. HIV/AIDS epidemic in the state of amazonas: characteristics and trends from 2001 to 2012. Rev Soc Bras Med Trop. 2015;48:70-8.

6. Pascom ARP, Meireles MV, Benzaken AS. Sociodemographic determinants of attrition in the HIV continuum of care in Brazil, in 2016. Medicine (United States). 2018;97:S69-74.

7. Pascom AR, Pinho RE, Rick F, Veras NM, Perini FDB, Meireles MV, et al Comparison of cumulative viraemia following treatment initiation with different antiretroviral regimens: a real-life study in Brazil. J Int AIDS Soc. 2019;22:e25397.

8. Chaves YO, Pereira FR, Pinheiro RdS, Batista DRL, Balieiro AAdS, Lacerda MVGd, et al. High detection rate of HIV drug resistance mutations among patients who fail combined antiretroviral therapy in Manaus, Brazil. Biomed Res Int. (submitted).

9. Mangal TD, Meireles MV, Pascom ARP, De Almeida CR, Benzaken AS, Hallett TB. Determinants of survival of people living with HIV/AIDS on antiretroviral therapy in Brazil 2006-2015. BMC Infect Dis. 2019;19:1-9.

10. Garrido MdS, Penna ML, Perez-Porcuna TM, de Souza AB, Marreiro LdS, Albuquerque BC, et al. Factors associated with tuberculosis treatment default in an endemic area of the Brazilian Amazon: a case control-study. PLOS ONE. 2012;7:e39134.

11. Magno EDS, Saraceni V, Souza ABD, Magno RDS, Saraiva MDGG, BührerSékula S. Factors associated with TB/HIV coinfection: evidence from notification data in the State of Amazonas, Brazil, 2001-2012. Cad Saude Publica. 2017;33:e00019315.

12. Da Silva LCF, Dos Santos EM, Neto ALDS, Miranda AE, Talhari S, Toledo LDM. Padrão da infecção pelo HIV/AIDS em Manaus, Estado do Amazonas, no período de 1986 a 2000. Rev Soc Bras Med Trop. 2009;42:543-50. 
13. Ford E, Puronen C, Sereti I. Immunopathogenesis of asymptomatic chronic HIV infection: the calm before the storm. Curr Opin HIV AIDS. 2009:43:206-14.

14. Appay V, Sauce D. Immune activation and inflammation in HIV-1 infection: causes and consequences. J Pathol. 2008;214:231-41.

15. Deeks SG, Phillips AN. HIV infection, antiretroviral treatment, ageing, and non-AIDS related morbidity. BMJ. 2009;338:288-92.

16. Sandler NG, Wand H, Roque A, Law M, Nason MC, Nixon DE, et al. Plasma levels of soluble CD14 independently predict mortality in HIV infection. J Infect Dis. 2011;203:780-90.

17. WHO. HIV/AIDS. 2021. https://www.who.int/health-topics/hiv-aids\#tab= tab.

18. Ferreira MD, Das Neves CP, De Souza AB, Beraldi-Magalhães F, Migliori GB, Kritski $A L$, et al. Predictors of mortality among intensive care unit patients coinfected with tuberculosis and HIV. J Bras Pneumol. 2018;44:118-24

19. Sattler FR, Chelliah D, Wu X, Sanchez A, Kendall MA, Hogg E, et al. Biomarkers associated with death after initiating treatment for tuberculosis and HIV in patients with very low CD4 cells. Pathog Immun. 2018;3:46-62.

20. Zachariah R, Spielmann MP, Harries AD, Salaniponi FML. Moderate to severe malnutrition in patients with tuberculosis is a risk factor associated with early death. Trans R Soc Trop Med Hyg. 2002;96:291-4.

21. Lakoh S, Jiba DF, Kanu JE, Poveda E, Salgado-Barreira A, Sahr F, et al. Causes of hospitalization and predictors of HIV-associated mortality at the main referral hospital in Sierra Leone: a prospective study. BMC Public Health. 2019;19:1-9.

22. Wiewel MA, Huson MA, van Vught LA, Hoogendijk AJ, Klein Klouwenberg PMC, Horn J, et al. Impact of HIV infection on the presentation, outcome and host response in patients admitted to the intensive care unit with sepsis; a case control study. Crit Care. 2016;20:1-10. https://doi.org/10. 1186/s13054-016-1469-0.

23. Getahun H, Gunneberg C, Granich R, Nunn P. HIV infection-associated tuberculosis: the epidemiology and the response. Clin Infect Dis. 2010;50:S201-7. https://doi.org/10.1086/651492.

24. Jiamsakul A, Lee MP, Nguyen KV, Merati TP, Cuong DD, Ditangco R, et al. Socio-economic status and risk of tuberculosis: a case-control study of HIV-infected patients in Asia. Int J Tuberc Lung Dis. 2018;22:179-86.

25. Pang W, Shang P, Li Q, Xu J, Bi L, Zhong J, et al. Prevalence of opportunistic infections and causes of death among hospitalized HIV-infected patients in Sichuan, China. Tohoku J Exp Med. 2018;244:231-42.

26. Phillips RO, Steinmetz A, Nichols J, Adomako E, Ofori E, Antonio E, et al. Spectrum of disease in HIV-positive patients presenting to a tertiary care hospital: a retrospective, cross-sectional review in Kumasi, Ghana. BMC Infect Dis. 2018;18:1-7.

27. Xiao J, Gao G, Li Y, Zhang W, Tian Y, Huang Y, et al. Spectrums of opportunistic infections and malignancies in HIV-infected patients in tertiary care hospital, China. PLoS ONE. 2013:8:1-10.

28. Mugusi SF, Ngaimisi E, Janabi MY, Mugusi FM, Minzi OMS, Sasi PG, et al. Risk factors for mortality among HIV-positive patients with and without active tuberculosis in Dar es Salaam, Tanzania. Antivir Ther. 2012;17:265-74.

29. Moodley A, Wood NH. HIV-associated oral lesions as an indicator for HAART failure: a review. SADJ. 2012;67:348-52.

30. Vagdatli E, Gounari E, Lazaridou E, Katsibourlia E, Tsikopoulou F, Labrianou I. Platelet distribution width: a simple, practical and specific marker of activation of coagulation. Hippokratia. 2010;14:28-32.

31. Zhang Z, Xu X, Ni H, Deng H. Platelet indices are novel predictors of hospital mortality in intensive care unit patients. J Crit Care. 2014;29:885 e1-885.e6. https://doi.org/10.1016/j.jcrc.2014.04.020.

32. Şahin F, Yazar E, Yildiz P. Prominent features of platelet count, plateletcrit, mean platelet volume and platelet distribution width in pulmonary tuberculosis. Multidiscip Respir Med. 2012;7:1-7.

33. Camon S, Quiros C, Saubi N, Moreno A, Marcos MA, Eto Y, et al. Full blood count values as a predictor of poor outcome of pneumonia among HIVinfected patients. BMC Infect Dis. 2018;18:4-9.

34. Mamik MK, Ghorpade A. Chemokine CXCL8 promotes HIV-1 replication in human monocyte-derived macrophages and primary microglia via nuclear factor-kB pathway. PLoS ONE. 2014;9:e92145.

35. Matsumoto T, Miike T, Nelson RP, Trudeau WL, Lockey RF, Yodoi J. Elevated serum levels of IL-8 in patients with HIV infection. Clin Exp Immunol. 1993;93:149-51
36. Ellwanger JH, Valverde-Villegas JM, Kaminski VDL, de Medeiros RM, Almeida SM, Santos BR, et al. Increased IL-8 levels in HIV-infected individuals who initiated ART with CD4+ T cell counts $<350$ cells/ $\mathrm{mm} 3$ - a potential hallmark of chronic inflammation. Microbes Infect. 2020;22:474-80.

37. Sun J, Su J, Xie Y, Yin MT, Huang Y, Xu L, et al. Plasma IL-6/IL-10 ratio and IL-8, LDH, and HBDH level predict the severity and the risk of death in AIDS patients with pneumocystis pneumonia. J Immunol Res. 2016;2016:1583951.

38. Andrade BB, Hullsiek KH, Boulware DR, Rupert A, French MA, Ruxrungtham $\mathrm{K}$, et al. Biomarkers of inflammation and coagulation are associated with mortality and hepatitis flares in persons coinfected with HIV and hepatitis viruses. J Infect Dis. 2013;207:1379-88.

39. Benito N, Moreno A, Filella X, Miró JM, González J, Pumarola T, et al. Inflammatory responses in blood samples of human immunodeficiency virus-infected patients with pulmonary infections. Clin Diagn Lab Immunol. 2004;11:608-14.

40. Ho HE, Peluso MJ, Margus C, Matias Lopes JP, He C, Gaisa MM, et al. Clinical outcomes and immunologic characteristics of coronavirus disease 2019 in people with human immunodeficiency virus. J Infect Dis. 2021;223:403-8.

41. Imperiali FG, Zaninoni A, La Maestra L, Tarsia P, Blasi F, Barcellini W. Increased Mycobacterium tuberculosis growth in HIV-1-infected human macrophages: role of tumour necrosis factor-a. Clin Exp Immunol. 2001;123:435-42.

42. Friedland J, Shattock R, Griffin G. Phagocytosis of M. tuberculosis or particulate stimuli by human monocytic cells induces equivalent Monocyte Chemotactic Protein 1 gene expression. Cytokine. 1993;5:150-6.

43. Lane BR, Lore K, Bock PJ, Andersson J, Coffey MJ, Strieter RM, et al. Interleukin-8 stimulates human immunodeficiency virus type 1 replication and is a potential new target for antiretroviral therapy. J Virol. 2001;75:8195-202.

44. Larsen CG, Thomsen MK, Gesser B, Thomsen PD, Deleuran BW, Nowak J, Skødt V, Thomsen HK, Deleuran M, Thestrup-Pedersen K. The delayedtype hypersensitivity reaction is dependent on IL-8. Inhibition of a tuberculin skin reaction by an anti-IL-8 monoclonal antibody. J Immunol. 1995; 155:2151-7.

45. Ameixa C, Friedland JS. Interleukin-8 secretion from Mycobacterium tuberculosis-infected monocytes is regulated by protein tyrosine kinases but not by ERK1/2 or p38 mitogen-activated protein kinases. Infect Immun. 2002;70:4743-6.

46. Pananghat AN, Aggarwal H, Prakash SS, Makhdoomi MA, Singh R, Lodha $\mathrm{R}$, et al. IL-8 alterations in HIV-1 infected children with disease progression. Medicine (United States). 2016;95:1-9.

47. Iii G, Inhibit N. Ga(III) nanoparticles inhibit growth of both Mycobacterium tuberculosis and HIV and release of interleukin-6 (IL-6) and IL-8 in coinfected macrophages. Antimicrob Agents Chemother. 2017;61:1-13.

48. Obirikorang C, Yeboah FA. Blood haemoglobin measurement as a predictive indicator for the progression of HIV/AIDS in resource-limited setting. J Biomed Sci. 2009;16:102

49. Medical P, Hospital C, College KM. Mortality and morbidity patterns among HIV patients with prognostic markers in a tertiary care hospital in southern India. 2011:273-6.

50. Kuller LH, Tracy R, Belloso W, De Wit S, Drummond F, Lane HC, et al. Inflammatory and coagulation biomarkers and mortality in patients with HIV infection. PLoS Med. 2008;5:1496-508.

51. Wada NI, Bream JH, Martínez-Maza O, Macatangay B, Galvin SR, Margolick JB, et al. Inflammatory biomarkers and mortality risk among HIVsuppressed men: a multisite prospective cohort study. Clin Infect Dis. 2016:63:984-90.

52. Lohman-Payne B, Gabriel B, Park S, Wamalwa D, Maleche-Obimbo E, Farquhar C, et al. HIV-exposed uninfected infants: elevated cord blood Interleukin 8 (IL-8) is significantly associated with maternal HIV infection and systemic IL-8 in a Kenyan cohort. Clin Transl Med. 2018. https://doi. org/10.1186/s40169-018-0206-5.

\section{Publisher's Note}

Springer Nature remains neutral with regard to jurisdictional claims in published maps and institutional affiliations. 